\title{
DÜBLIN
}

Technological University Dublin

ARROW@TU Dublin

\section{Gender Representation in Children's Books: Case of an Early Childhood Setting}

Katarina Filipovic

Technological University Dublin, katarina.filipovic@tudublin.ie

Follow this and additional works at: https://arrow.tudublin.ie/cserart

Part of the Early Childhood Education Commons, and the Social and Behavioral Sciences Commons

\section{Recommended Citation}

Katarina Filipović (2018) Gender Representation in Children's Books: Case of an Early Childhood Setting, Journal of Research in Childhood Education, 32:3, 310-325, DOI: 10.1080/02568543.2018.1464086

This Article is brought to you for free and open access by the Centre for Social and Educational Research at ARROW@TU Dublin. It has been accepted for inclusion in Articles by an authorized administrator of ARROW@TU Dublin. For more information, please contact arrow.admin@tudublin.ie, aisling.coyne@tudublin.ie, gerard.connolly@tudublin.ie.

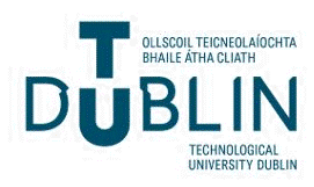




\section{Gender Representation in Children's Books: Case of an Early Childhood Setting}

\section{Katarina Filipović}

To cite this article: Katarina Filipović (2018) Gender Representation in Children's Books: Case of an Early Childhood Setting, Journal of Research in Childhood Education, 32:3, 310-325, DOI: 10.1080/02568543.2018.1464086

To link to this article: https://doi.org/10.1080/02568543.2018.1464086

\section{Published online: 14 May 2018.}

Submit your article to this journal ๘

Џll Article views: 5776

Q View related articles $\asymp$

View Crossmark data 5

4

Citing articles: 2 View citing articles $₫$ 


\title{
Gender Representation in Children's Books: Case of an Early Childhood Setting
}

\author{
Katarina Filipović (D) \\ Dublin Institute of Technology, Dublin, Ireland
}

\begin{abstract}
The purpose of this small-scale case study was to identify and analyze key patterns in terms of gender representation in children's books in one early childhood setting. Furthermore, this case study sought to understand the perspectives of early childhood educators on gender representation in children's books. The researcher employed multiple methods of data collection, including content analysis of 15 children's books, as well as reflective journal writing and professional conversation between eight educators from one early childhood center in Dublin, Ireland. Content analysis of children's books revealed distinct gender patterns that include underrepresentation of female characters and instances of gender stereotyping. Further findings indicate that educators exhibit a lack of awareness of gender patterns and attribute limited importance to gender representation in children's books. This research hopes to aid early childhood educators in becoming aware of gender stereotyping in children's books, enhancing observation and reflective skills, and creating a more inclusive learning environment.
\end{abstract}

\section{ARTICLE HISTORY}

Received 17 July 2017

Accepted 7 January 2018

\section{KEYWORDS}

Children's books; early childhood education; gender representation; gender stereotypes

Children's literature has a long and rich history, dating back to the mid-18th century (Hunt, 2009) and represents an important part of popular culture (Adams, Walker, \& O'Connell, 2011). In most societies, storytelling is one of the most important ways of transmitting cultural norms, values, and attitudes to young children (Cherland, 2006). Children's books have an important role in the process of social learning and identity development (Paterson \& Lach, 1990; Ruterana, 2012), providing children with some of their earliest and longest lasting perceptions of gender, race, and class (Frawley, 2008). Alongside other factors, books contribute to children's understanding of expectations associated with gender and shape the many ways in which they understand their place in society as girls and boys (McCabe, Fairchild, Grauerholz, Pescosolido, \& Tope, 2011).

One of the first major studies on gender roles in children's literature conducted by Weitzman, Eifler, Hokada, and Ross (1972) examined Caldecott Award-winning children's picture books and found gender stereotyping and underrepresentation of female characters. The authors concluded that children "are bound to receive the impression that girls are not very important because no one has bothered to write books about them" (Weitzman et al., 1972, p. 1129). More recent studies (Diekman \& Murnen, 2004; Gooden \& Gooden, 2001; Hamilton, Anderson, Broaddus, \& Young, 2006; McCabe et al., 2011; Nair \& Talif, 2010; Paynter, 2011) show that even in the 21st century, despite equality and diversity becoming central in education, children's books continue to represent genders in stereotypical ways and to underrepresent females. Such stereotypical depictions and the associated unbalanced presence of female and male characters have implications for children's construction of gender in early childhood (McCabe et al., 2011). 
Studies show that exposure to gender stereotypes negatively affects girls and boys, limiting the scope of acceptable roles and behaviors, and normalizing gender inequalities (Adams et al., 2011). The consequences of gender stereotyping are reflected in children's activity choices, career aspirations, and academic outcomes (Aina \& Cameron, 2011; Tagnoli, Pullen, \& Lieber, 1994). Female invisibility could lead to the belief that girls are less important, and stereotyping of roles and activities are likely to reinforce the gender system, limiting girls and boys in their aspirations. For example, research suggests that male characters are favored by boys and girls, perpetuating the idea that girls are less interesting than boys (McCabe et al., 2011). Four-year-old children have already been found to associate male characters with supremacy, while associating female characters with dependency (Davies, 2003). It is reasonable to link these preferences and associations to the aforementioned stereotyping and underrepresentation of female characters.

Continuous exposure to stereotyped content can have serious consequences, making biases part of children's thinking, especially when they are reinforced by society (Santora, 2013). On the other hand, nonstereotypical books "produce positive changes in self-concept, attitudes, and behavior" (Aina \& Cameron, 2011, p. 16). Ruterana's (2012) research in Rwanda showed children of both genders reacting positively to a female character portrayed in traditionally male roles, which in the past have been culturally unacceptable for females to perform. This highlights the need for exposure to nonstereotypical literature, depicting diverse role models for young children. The need for more studies on gender representation in children's books exists; "since children begin to understand gender and apply gender stereotypes to themselves at an early age, we can reasonably ask what such books are teaching children about gender" (Taylor, 2003, p. 308).

Diversity of characters in books for children is important because children need to see characters like themselves represented in the media to not to feel excluded (Crisp et al., 2016). When children cannot see themselves represented in books it can affect their sense of self-value (Santora, 2013). It is the responsibility of adults, at home and in educational settings, to provide high-quality learning resources to children. To be able to achieve this, adults have to become aware of gender representation issues and critically reflect on the content of children's books and the messages they are conveying.

The majority of studies on gender issues in children's books focus exclusively on the awarded or best-selling children's books, while there is a noteworthy absence of research concerning children's books read in early childhood settings, such as day-care or preschool. In the conclusion to their study, Gooden and Gooden (2001) identified this research gap and recommend shifting the focus to preschool materials. Children's books are one of the main aspects of the environment in early childhood settings that influence children's perceptions of gender and gender stereotypes (Huntington, 2013). Focus on children's experiences in early childhood settings is important because everyday experiences and the treatment of children in these settings have a significant impact on the child's construction of gender (Karlson \& Simonsson, 2011).

The support children get during early childhood will lay the foundation for the future formation of children's gender identity (Derman-Sparks \& Edwards, 2010). This underlines the importance of not only children's books and other reading materials found in the settings, but also, even more strongly, the crucial role of early childhood educators. Educators who are reflective and aware of different factors influencing the development of gender identity can counteract the formation of gender stereotypes and help children develop a positive sense of gender identity (Aina \& Cameron, 2011; Zaman, 2008). These findings emphasize the need for further research conducted in the context of early childhood settings. Such research can help early childhood educators become more aware of the possible underrepresentation and stereotyping in children's books, while contributing to enhanced observation and reflective skills with regard to the choice of books they are reading to and with young children. Being aware of gender differences and diversity allows educators to create an inclusive learning environment (Dewar, Servos, Bosacki, \& Coplan, 2013).

In light of the arguments outlined above, the main purpose of this study was to explore gender representation in children's books currently being used within early childhood settings. This study 
aimed to include educators in collaborative critical reflections on the topic of gender representation in children's books and to understand educators' perspectives regarding this issue. The following research questions were addressed:

(1) What are the patterns of gender representation evident in children's books in one early childhood setting?

(2) To what extent are these patterns recognized and acknowledged by early childhood educators working within this setting?

(3) What are the views and beliefs of early childhood educators on gender representation in children's books within this early childhood setting?

\section{Methods}

To fulfill its main objectives, this research was designed as a small-scale case study employing multiple methods of data collection including content analysis of 15 children's books, as well as reflective journal writing and a professional conversation between eight educators in one early childhood center in Dublin, Ireland. This research design was adopted because it was well suited for an in-depth understanding and exploration of the research topic.

\section{Context and participants}

The research study was conducted in one community-based early childhood center in the inner city of Dublin. Eight early childhood educators working with three different age groups-waddler (12 months-24 months), toddler (2-3 years), and preschool (3-5 years)-were chosen as participants. During the first meeting with the participants, the researcher personally introduced the research study and answered all the questions participants had. All participants agreed to be part of the research study and signed consent forms.

Participants were asked to provide demographic information, such as education level and years of practice, during the journal writing phase. However, only one half of the participants decided to share this information. The researcher decided to respect participants' wish to not disclose that information; therefore, participants' demographics were not part of analysis and discussion. However, it is worth noting that in Ireland all staff working directly with children must hold a minimum of a Major Award in Early Childhood Care and Education at level 5 on the National Framework of Qualifications.

Identifying information with regard to the early childhood setting and the participants in the research study was anonymized. All names appearing in this article are pseudonyms.

\section{Phase one: Content analysis}

During the first phase of data generation, content analysis was used for examination of children's books in one early childhood setting to describe and understand the ways in which gender is represented in those books. Nair and Talif (2010) make a distinction between overt and covert markers of sexism in children's literature. Overt markers include the frequencies with which female and male characters appear as main characters in texts and illustrations, whereas covert markers manifest through the subtle use of language. For the purpose of the present study, the researcher decided to combine a quantitative and qualitative approach to content analysis, using overt and covert analysis. Quantitative frequency count was used to explore male-to-female ratio in text and in illustrations to be able to present an informative, concise, and clear report for the research participants. Furthermore, a qualitative content analysis was employed to identify covert markers of inequality and stereotyping and to explore subtler indicators of gender patterns in sampled books. 
Children's books for the content analysis were identified by the educators as being the preferred and frequently used books in that early childhood setting. It is worth noting that this study explored the research problem from the perspective of educators and that the sample therefore contains books that are preferred and often used by the educators themselves. This study did not explore children's perspectives or their preferred books. Participants identified books by filling in a sampling form in which they noted the book title, authors, illustrators, publishers, and children's group that the book originated from. Books were sampled from three different age groups in the participant early childhood center: waddler, toddler, and preschool group, resulting in the final sample of 15 books (Appendix A).

\section{Phase two: Reflective journals}

After the researcher conducted the content analysis of the sampled books, the results of the analysis were given to the participants so they could familiarize themselves with gender patterns found in books and reflect upon the analysis results. The researcher created reflective journal writing guidelines for participants that explained the purpose of reflective journals and provided reflective journaling instructions. Participants were instructed to read an attached summarized analysis of the books and to write down their thoughts, opinions, and reactions in the form of a reflective journal.

The purpose of this phase was to collect initial data concerning participants' views on gender representation in the analyzed books and to prepare participants for a focus group discussion. Collected data were also used to help the researcher develop relevant questions for focus group discussion.

\section{Phase three: Focus group}

Focus group questions were developed and sequenced using the framework model of professional conversation (Irvine \& Price, 2014). In their 2014 research study, Irvine and Price created a series of preplanned questions by adapting Stanfield's (2000) four-level question framework for focused conversation in the workplace. According to Irvine and Price (2014), the main idea of professional conversation "is to draw together early childhood educators to engage in a constructive dialogue on a topic of shared interest and importance" (p. 87). Because this approach includes critical reflections, sharing views, and deepening knowledge and understanding, it was selected as a methodological approach that was clearly aligned to the aim and design of the research study.

\section{Data analysis}

The process of data analysis was divided into two separate stages. First, the content analysis of sampled children's books was conducted prior to gathering of other data. Strategies used in the content analysis originated from "Nordic website for the promotion of gender equality in children's literature and day care," which presents educators with strategies for gender analysis of children's books (Reform, 2016). Out of the six analysis strategies available on the website, the first three-The Counter, The Picture Reader, and the Norm Critic-were identified as being relevant for the research study. Analysis strategies from the website were further developed and adapted to fulfill the needs of the research study. The following three strategies were used to analyze sampled books:

(1) The Counter - What is the gender of the title character, the main character, and all other characters in the book?

(2) The Picture Reader - What is the gender of the character appearing on the front cover? How many male and female characters are illustrated in the book? Which gender patterns can be identified in illustrations? 
(3) The Norm Critic - How are the main characters of different gender described? What are the roles? What gender norms are evident in the text and illustrations?

An analysis form (Appendix B) was created to systematically examine the content of the sampled books, whereas analysis strategies and guidelines were developed to guide the analysis process and define the units of analysis. Based on the findings of the previous studies (Diekman \& Murnen, 2004; Gooden \& Gooden, 2001; Hamilton et al., 2006; McCabe et al., 2011; Nair \& Talif, 2010), the following elements of children's books were identified as being of importance for the research study and for that reason included in the analysis form: characters count, illustrations count, main characteristics attributed to the characters, activities carried out by the characters, characters described as being active or passive, the majority of time spent inside or outside, nurturing and parenting behavior, and character's occupation.

After analyzing all 15 children's books, the results of the content analysis were summarized to generate a clear and concise report for the participants. Data collected during this phase of the research study were used to generate discussion and reflective thinking during the two data collection phases. Research participants were asked to use the content analysis report as a starting point of critical reflection during the phase of reflective journaling. Furthermore, the results of the content analysis were part of the collaborative discussion during the professional conversation.

The second part of the data analysis process included a thematic analysis of reflective journals and professional conversation. Both data sets were brought together for thematic analysis and no distinction is made between information coming from the two sources of data. The researcher employed a thematic analysis procedure identified by Braun and Clarke (2006), following a number of sequential phases: familiarization with data, generation of initial codes, searching for themes among codes, reviewing themes, defining and naming themes, and producing the final report. Once coded and categorized, data were analyzed to identify patterns and produce themes and subthemes. The researcher revisited the transcripts throughout the process of the analysis, exploring the ways in which different segments of data related to developing themes to refine codes and themes. Identified themes were then clearly defined and named, and data within them were further analyzed to identify the "essence" of each theme (Braun \& Clarke, 2006, p. 100).

\section{Results}

\section{Gender patterns in children's books}

\section{The counter}

The content analysis showed male characters dominating every examined category. Specifically, out of the 16 title characters, 14 characters were male, whereas only one was female. Similarly, out of 14 main characters, 10 were male and, again, only one was female. Summarizing findings from the analysis of all characters appearing in the books, there were three times more male characters than female characters.

There was a significant percentage of neutral characters in the "all characters category. Out of 71 characters, 28 characters (39\%) were coded neutral. This high number of neutral characters follows from the fact that a large number of sampled books featured exclusively animal characters or a high number of animal characters. During the coding process, all animals that were not specifically referred to in gendered ways were considered to be neutral. In all three categories, there were more neutral characters than female characters. This was most prominent in the "all characters" category, where only $16 \%$ were female characters in contrast to $39 \%$ as neutral characters. However, the male characters greatly outnumbered female and neutral characters, with $45 \%$ of all characters, $82 \%$ of title characters, and $72 \%$ of main characters being male. 


\section{The picture reader}

For each book, the gender of characters in illustrations was counted. Gender was counted for book cover illustrations and for all character illustrations. Additionally, illustrations were examined through a qualitative content analysis to identify gender patterns in the characters' physical depictions, setting, and/or activity and colors used in illustrations. This was done in order to determine whether there is a tendency to depict characters in a gender-stereotyped way.

Male characters dominate illustrations in the sampled books. Out of 498 analyzed illustrations, 205 are male illustrations and 97 are female illustrations. In other words, there were twice as many male illustrations as there were female illustrations in the analyzed books. Furthermore, there were significantly more neutral illustrations (39\%) than there were female illustrations $(20 \%)$. It is worth noting that there were no cover illustrations in the book sample that featured female characters. Out of 15 cover illustrations, 11 were male and four were neutral. In other words, $73 \%$ of all book covers depicted either a single male character or a picture where male characters were dominant. The remaining $27 \%$ of covers were neutral, and no cover featured a picture of a female character. This included human and animal characters.

Some authors argue that illustrated neutral animal characters that lack feminine markers (long lashes, bows, pigtails) are understood to be male by children (Marie, 2007). If this argument was taken into account, the domination of male characters in the illustrations would become even more prominent. Furthermore, this indicates that the male seems to be a default form. Examples of this can be found in the analyzed book Dear Zoo, where all animals were referred to as "he." Out of eight animals mentioned in the book, none was female. Animals seemed to be illustrated and potentially perceived as male, unless specifically indicated as being female. It would appear that female animals make an appearance mostly as part of a couple (Elephant Pants, Monkey Business) or as a mothering figure (Owl Babies, Monkey Puzzle).

Feminine markers (long lashes, full lips) that are typically used to distinguish female animals from male animals were prominent in the book Monkey Business. Although males were illustrated as "just animals," female animals were given prominent stereotypical features of human females. Interestingly, in Elephant Pants, a book by the same authors, the feminine nature of nonmale animals was further emphasized by illustrating female animals as wearing bras, even though none of them was illustrated as having breasts. It seems that the ideas of modesty and appropriateness are transferred from the human to the animal world in children's books. To signal femininity of one half of an animal couple, the illustrator reached for a way to depict the "rules of femininity" present in human society. Even though the female animals were obviously not in need of a bra, it was there to ensure that these animals were perceived as being female. This further supports the idea that the male form is a given, whereas the female form has to be established through the use of stereotypical feminine markers.

Ways of using clothing to differentiate genders is another interesting aspect of gender representation in children books. In We're Going on a Bear Hunt, mother and daughter were illustrated wearing dresses, whereas males wore trousers and sweaters. Males appeared to be dressed in much warmer clothes, appropriate for the adventure. Illustrations showed a family facing different kinds of terrains and weather conditions, including walking through a snowstorm. Facing these conditions, females dressed in thin summer dresses must have been freezing. However, as in much of real-life female clothing, comfort was sacrificed to preserve feminine beauty standards.

An interesting finding in the present study is the lack of any apparent association between gender and particular colors. Colors and the ways they were used in relation to the gender of the main characters were analyzed under The Picture Reader strategy. However, there were no indications that dominant colors in the picture-books had any connections to the gender of the main characters. Colors were predominately related to the environment and the setting of the plot. Because large numbers of stories in the analyzed book sample revolved around animals in their natural environment, dominating colors usually included different shades of green, blue, brown, and yellow. 


\section{The norm critic}

The norm critic analysis strategy focused on text and illustrations that portrayed characteristics attributed to main characters and activities in which characters engaged. Attributed characteristics included physical appearance, behavior, and emotions shown by the character. Furthermore, in line with previous research studies (Hamilton et al., 2006; Kortenhaus \& Demarest, 1993; Louie, 2012; Taber \& Woloshyn, 2011; Toçi \& Aliu, 2013), the following character attributes were examined: activity/passivity, spending time indoors/outdoors, nurturing behaviors, and character's occupation. This analysis strategy was used to examine specificities of gender representation in sampled books and identify evident gender norms.

Findings showed a lack of female characters and the presence of distinctive gender patterns. Female characters were typically underrepresented and depicted in a gender stereotypical way in the role of wives and mothers. On the other hand, male characters were typically shown in active main roles. Only one book, Owl Babies, had a female character in the title and as a main character. This character was Sarah, one of the baby owls. However, even this one female main character was part of a dominantly male group. She appeared to be the oldest sister to two younger male owls. There were no individual main characters that were female in any of the books. Eight books had no type of female characters in them. The remaining seven books had a certain number of female characters. However, these females mostly appear as secondary or background characters.

Representation of gender through characters in children's books is interesting in terms of the roles highlighted, particularly with regard to family roles and responsibilities. Female characters mostly appeared in the role of mothers or mothering figures, or in the role of a wife. In four out of seven books, female characters were presented solely as mothers (Owl Babies, The Very Busy Bee, Monkey Puzzle, and Supermarket Zoo). These characters had no name or identification marker other than "Mother." In Owl Babies, Sarah, the only main character in the analyzed book sample, exhibited nurturing and mothering behavior despite being a child character herself. In the absence of the Mother Owl, she took care of her younger brothers. As a caring older sister, she encouraged and comforted them, inviting them to sit on her branch. This type of depiction reinforces the idea that females are the ones who nurture and comfort. The nurturing and mothering role for females was also noted in the character of Snail in The Very Buzzy Bee. Snail was referred to as her, and she was the only character described as taking care of her children. The only other female character in this book was Caterpillar, who was described as eating and sleeping. On the other hand, male characters like Dung Beetle and Dragonfly were depicted working, having fun, and being daring.

Although females mostly had a mother role, appearances of fathers were rare. Characters of mothers appeared in five books, while there were only two fathers. Their nurturing roles and emotional value seemed to be limited. Father monkey in Monkey Puzzle was shown as having little importance. Although the mother was described as being very important to the little monkey who was searching for her throughout the book, the father seemed not to have any significant role. He had no apparent emotional value to the little monkey. Father made his appearance toward the end of the book to take the little monkey to see its mother. Although the little monkey was excited to finally see his mother, he showed no signs of love for his father. This reinforces the idea of mother as a primary caregiver and is in line with the findings of Anderson and Hamilton's (2005) study indicating that fathers tend to be underrepresented, characterized as ineffectual parents, and less likely to be involved in child care. The only appearance of a nurturing father was found in We're Going on a Bear Hunt. However, this character only appeared in illustrations. Although the text of this book did not mention specific characters or roles they are fulfilling, the illustrations showed the father taking care of a young child together with the mother.

Analyzed dimensions of active/passive, appearing inside/outside, and character's occupation had little relevance for this particular book sample. A large percentage of books featured animals in their natural environment. For this reason, they were tied to the outside spaces, regardless of gender. For the same reason, the range of characters' occupations was very limited. Furthermore, the almost 
complete lack of female main characters did not allow for effective comparison of female and male characters in regard to being described as active or passive.

\section{Educators' perceptions of gender in children's books}

Overwhelmingly, early childhood educators expressed a lack of awareness regarding gender patterns in books they often used with children. When reflecting upon the results of the content analysis performed on the book sample identified by them as preferred and often-read books in the early childhood center, surprise was a dominant reaction.

Mary: I was surprised. The first thing when I read it... My first thing was like-no, no, no, hang on a minute, that's not right. Like, you did not get that right, because I just didn't even really pay attention to how many, you know, characters were male from page or whatever, you know I was like-really? We were just discussing-is it really in that book that is only just boys or girls, you know...

This is very surprising and thought provoking when I consider the impact books can have on children and their views. Gender roles in children's books are not something I would consider before. The research shows that books can affect children's long-term perceptions of gender roles; this is something I found very interesting and I will keep that in mind in the future. (Reflective Journal 4)

Even though all participants expressed surprise about the dominance of male characters in the analyzed books, the significance they gave to it differed from person to person. Although some educators were surprised but not concerned about gender patterns discovered in books, others considered this discovery to be thought provoking and possibly relevant for their future practice. Educators who perceived the gender of characters as something that is not important claimed that gender was not and will not be something to think about when choosing books. They supported these claims by arguing that the children they work with do not acknowledge the gender of the characters in books. The general attitude that these participants held could be summarized as "books are only books." They understood the plot of the book and characters that inhabit that plot as existing outside of the sphere of gender. The way gender was represented in books had no real impact on young children because children did not see gender in books. Jane expressed it in the following way, "But, to me, like, children look at people in books as characters you know, like everybody can be a superhero, everyone can be a princess, everyone can be a fireman or a firewoman."

Children's perception of characters in books was understood to be guided by a uniform understanding of the book's protagonists as genderless beings there to propel the plot, without existing inside the story as a boy or a girl, male or female. An illustration of this viewpoint is that "a frog will always be a frog," whereas the gender of the frog remains of no relevance. Although children's needs and desires to identify themselves with the characters in books were mentioned, this identification was not seen as being connected to the gender of the characters. However, the possibility that continued exposure to gender stereotypes could negatively affect children and their gender development was acknowledged.

Despite the general agreement that children at a young age do not understand gender differences and for that reason are not affected by gender stereotypes, some educators expressed concern over the implications of continuous exposure to stereotypical literature. A prominent concern revolved around the possibility that stereotypes present in books could reinforce gender stereotypes already present in children's environment, such as mothers being depicted primarily in the kitchen or performing other domestic tasks. Gender representation in books was seen as something that could not be a primary factor in developing stereotypes but could further strengthen those stereotypes and in that way have an impact on children. Children's books were seen as secondary to media influences and home-life experiences and for that reason were given minimal consideration. Overall, books were used to achieve educational goals that did not include gender development. Educators repeatedly noted that issues of gender equality were addressed through gender neutral practices in the center, while books were used to address other aspects of children's learning and development. 


\section{Educators' image of a child}

Participants' reflections included discussions on the way they think about and perceive the children with whom they work. These perspectives can be considered to be educators' images of the children because they include distinct ideas regarding child's development, behavior, and inner psychological processes. Careful analysis of participants' reflection uncovered a number of distinct elements that make up the image of a child held by educators. Participants conveyed ideas of a child as innocent and unaware, a child as a "sponge," and a child as storyteller and creator. In regard to gender identity, participants held the image of a child as gendered and unaware of gender issues, indicating that gender identity and gender representation in the early years remain complex and underexplored topics.

The notion of children as "innocent beings" with a limited understanding of gender was prevalent in educators' narratives. Children were perceived as not being aware of gender in books and, due to their innocence, as not having any need to discuss topics related to gender. The idea that children should not be prompted to talk about gender was prominent. When speaking about the possibility of discussing gender representation in books with children, Jane shared the following opinion:

\footnotetext{
It's not something we need to bring their attention to at such a young age. Yeah, it's unknown to them. They're innocent at this age and don't think, you know. They are only innocent as so young and I think it's something that their attention doesn't need to be brought to.
}

Jane seemed to perceive the topic of gender as something that is in conflict with the concept of innocence in young children. A child's innocence was seen as something to be valued and protected because it was perceived as a short and fleeting period of human life. Keeping children's focus on characters and the story outside of the dimension of gender seemed to be a way for educators to preserve children's innocence.

However, another somewhat contradictory idea was expressed by some educators regarding the way children may be influenced by gender representation in books. Even though children were seen as unaware of gender and for that reason largely unaffected by the way gender was represented in literature, children were also viewed as open to external influences. Some educators expressed a view of children as "blank pages." In relation to that, Mary said:

That is how it is. You know you always say that children are so like blank pages and that they are open to everything that us, the society that is putting ideas in their heads and that's exactly what it is, comes out of the books as well.

In relation to this view, educators assumed that children who are open and innocent can be easily influenced by society. Books were then seen as the prolonged arm of society that transmits cultural values, filling in the "tabula rasa" that the inexperienced and open child appeared to be. Through this, educators recognized the potential relation between gender in books and the development of children's gender identity.

An interesting finding was that children were recognized as storytellers and creators. Specifically, children were perceived as creating not only the stories they were telling, but also their own gender identities. Despite the general attitude that children do not recognize gender (in books), when discussing children as creators of stories, certain gender stereotypical behaviors were identified. Jane noted the following, "I did story stick last week. Like, I passed something around and we all had to tell a story, but boys kept bringing up monsters and dinosaurs into it, while girls were saying they were princesses." It seems that active involvement in the creation of a story was seen as strongly connected to the expression of child's gender, whereas reading or being read to was understood as a relatively passive activity that did not lead to gender patterns being recognized by children.

\section{Role of educators in addressing gender issues in early childhood}

Two key findings emerged with regard to the potential impact educators can have on the way gender is understood in books. The first of these findings related to how educators interpret the content of 
books, whereas the second one included the choice of messages being delivered by the educators. Within these narratives, emphasis was placed on the presentation over the content of the book. There was an agreement that the way educators interpret books is what matters most in work with children. Tess explained:

Thinking in relation to books, it's kinda about how you interpret the books as well. Like, you can kinda base it, like you can have a book with loads of words in it and you can interpret it to like what kids' interest are and what you want to teach children on that particular day.

Educators perceived their storytelling roles as complex and multilayered. Reading a book to children included processes of choice, interpretation, and creation. Siobhán addressed the idea that early childhood educators (ECEs) not only interpret and change the content of the books while reading to children, they also actively choose the messages that are conveyed to children, "The message we need to get across is what we get across, not always the message that the book is actually about."

A dominant idea conveyed by the majority of participants during focus group discussion was that ECEs, being professionals, have many important responsibilities toward the children in their setting. For some educators, these responsibilities included presenting books in a gender neutral way:

I feel that how gender roles are depicted in books can reinforce conformity if the books are not presented in a gender neutral way and this is the responsibility of early years practitioners.... Unfortunately, I think gender is an issue that is not really acknowledged in books for children; however, I feel that a good service where the early years practitioners are trained and have a good knowledge of diversity and emphasis is on how the books is presented to the children and at this point there is an opportunity for the EYP to discuss gender roles and challenge stereotypes. (Reflective journal 4)

In this way, gender representation in books was acknowledged as an underexplored topic in the context of an early childhood center. Training, knowledge, and shared reflections were identified as a means of achieving a gender neutral environment where children are treated as individuals with diverse needs and characteristics.

\section{Discussion}

With particular reference to the results of the content analysis, certain patterns of gender representation, including female underrepresentation, treating male as a given form, and specific patterns of gender stereotyping in the context of family, were identified. These results are in line with previous research studies (Hamilton et al., 2006; McCabe et al., 2011; Nair \& Talif, 2010; Paynter, 2011; Ruterana, 2012; Tsao, 2008) that found underrepresentation of female characters and gender stereotyping to be common in children's books. Findings therefore suggest that traditional stereotypical gender patterns still prevail in children's books used in the participating early childhood setting.

McCabe et al. (2011) point out that lack of female characters in central roles may encourage children to accept female invisibility and subsequently lead to the belief that girls are less important and less interesting than boys. Following this argument, the almost complete lack of female main characters in the analyzed books has the potential to negatively influence young girls' self-image. Therefore, gender underrepresentation of this sort could be seen as a red flag indicating a lack of gender-sensitive materials. However, findings from the professional conversation with educators did not reflect this view of the potential negative impact of gender underrepresentation in children's reading material. In fact, in stark contrast to the ideas conveyed by the analyzed literature (McCabe et al., 2011; Ruterana, 2012; Tagnoli et al., 1994; Tsao, 2008), the present study findings indicate that educators do not find gender representation in books to be impactful on the child's construction of gender.

Finally, considering the predominant role that family is given in children's lives by the educators, an interesting finding is the lack of caring father figures depicted in children's books and the restriction of female characters to the roles of mothers and wives. This is especially relevant because 
educators' perceptions of gender representation in the present study seem to revolve mainly around gender roles in the family. Similar to the findings of Anderson and Hamilton's (2005) study where fathers have been found to be underrepresented and stereotyped as absent and ineffective parents, findings of the present study show that fathers are mostly missing or seen as being of secondary importance. On the other hand, female characters are almost exclusively represented as mothers or wives, without having any other role in the plot. This indicates that the traditional gender roles of females as carers inside the home and males as providers outside the home (Diekman \& Murnen, 2004; Hamilton et al., 2006) are prevalent in the sampled children's books.

Family aspects of gender roles seem to be the most important dimension of gender representation to the educators, who expressed clear ideas of supporting a more progressive view of children's mothers rather than stereotypical ideas of housewives whose jobs are primarily cleaning and cooking. Given the importance that educators attributed to family aspects of gender roles, it is clear that the roles that educators support and the roles that are actually represented in children's books are not well aligned. The question arises, then, as to whether these differences are deemed important enough to educators in order for them to address these patterns and make a step toward changing them. Taking into consideration the crucial role educators play when choosing and reading books to young children (McCabe et al., 2011), their understanding of these differences is crucial for initiating any sort of change in how the appropriateness of the content of books used in early childhood settings is judged.

The importance of reading books to children as an instrument for conveying values and concepts was highlighted in the study findings. Educators' storytelling roles were perceived as complex and multilayered, including processes of choice, interpretation, and creation. Participants explained that they often modify books when reading in order to include messages they find to be suitable for children. Such findings are consistent with previous research where it was found that teachers do not read books verbatim to children (Patt \& McBride, 1993). Educators were aware of certain modifications they made to the books being read to convey certain messages or to achieve a particular effect. They not only interpret and change the content of the books while reading to children, but also actively chose the messages they were conveying to children. Such findings prompt consideration of the fact that the way in which adults interpret books for children may have even more impact on children's understanding of gender roles than the actual content of the books (Kok \& Findlay, 2006). This, in turn, suggests that educators can potentially use this influence to include more gender diversity and fight stereotyping in children's books. However, to do this, those educators first need to be aware of the gender patterns in books, understand them as potentially harmful, and make a conscious effort to transform harmful materials into gender-sensitive narratives.

\section{Personal gender theories and their influence on educators' practices}

The view of children as unaware of gender and therefore unaffected by stereotypes prominent in books could be influenced by educators' personal gender theories and the image of a child they hold. As highlighted by Karlson and Simonsson (2011), different understandings of gender development and different gender discourses operating in early childhood settings can contribute to different practices. These differences occur depending on the educator's perception of gender development as an inner psychological process, a process of socialization, or through the poststructural lens of construction and negotiation. Educators' understanding of gender has an essential role in the construction of gender messages that children receive and influences the ways in which educators use these materials in their work with children. For example, children who are perceived as socialized are seen as formed by outside forces, whereas processes of construction and negotiation emphasize children's active ways of acquiring gender depending on discourses dominating their context (Karlson \& Simonsson, 2011).

Furthermore, educators' image of a child can influence the way in which they behave and interact with children (Malaguzzi, 1993; Tainio \& Karvonen, 2015). Analysis of participants' 
reflection uncovered a number of distinct elements that make up the image of a child held by educators. Participants conveyed ideas of a child as innocent and unaware and of a child as a "sponge." The notion of children as innocent beings with a limited understanding of gender was prevalent in educators' narratives. Children were perceived as not being aware of gender in books and, due to their innocence, as not having any need to discuss topics related to gender. In relation to this view, educators assumed that children who are open and innocent can be easily influenced by society, confirming their understanding of gender as being a process of socialization.

Because educators seemed to understand gender as being primarily constructed through socialization, it would be natural to assume that they would recognize books as a medium that transmits societal influences. However, this was not the case with this particular group of educators. Participants not only held a specific view of gender as socially constructed, but also had rigid understandings of how processes of socialization work. Books were perceived as having low potential for transmission of societal rules and values regarding gender roles. As findings show, educators were mainly concerned about the stereotypes in the environment outside the early childhood center. Family influences and messages transmitted through the other types of media were seen as having a major influence on children's gender development. On the other hand, children's books were perceived as not having any strong influence on development of gender stereotypes. Importance given to the family and the media indicates that educators perceive the environment outside the early childhood settings as having a greater influence on children's construction of gender, whereas the environment that they control is perceived as having limited influence.

Particularly interesting is the finding that while some media formats, such as television, are seen as having a strong impact on the construction of gender, children's books as a media type are perceived as having an extremely low impact on children. These perspectives differ substantially from a significant body of literature that provides evidence of the important role books have in children's early development. In terms of language development, an emphasis is put on the importance of shared reading from an early age (Raikes et al., 2006). Blake and Maiese (2008) showcase the enormous influence shared reading can have on children's language developments, as well as having a great role in emotional and personality development. Through stories, children learn to make meaning of the world around them, accept different perspectives, develop personal goals, connect with others, and learn to value each other (Lowery, 2002). Finally, children's books help young children learn social norms, whereas the main characters serve as role models that shape children's perceptions of femininity and masculinity (Aina \& Cameron, 2011). In this way, children's books play an important role in reproducing gender norms and shaping children's perceptions of gender (Roper \& Clifton, 2013). When the majority of the characters are male, with rare female characters typically portrayed in stereotypical traditional roles, as is the case with the analyzed book sample, children are left with a limited range of role models in literature.

Furthermore, findings suggest that educators may have conflicting ideas about gender in the early years that can be affected by personal experiences and beliefs. Although children's gendered behaviors are recognized in certain areas of practice, such as play and dressing up, children's perception of gender in literature is deemed as insignificant. The main reason for these attitudes seems to be educators' limited personal experiences with recognizing gender patterns in books. In this way, personal gender theories held by educators may cloud their judgment and limit their capability to be objective and unbiased. Attitudes and personal beliefs can influence educators' interactions with children (Dewar et al., 2013), even when they are unaware of how their biases influence the ways they talk and act (Larrivee, 2000). Because children's books are not ideologically neutral and selecting books for children is "a political decision-making process" (Short, 2001, as cited in Marie, 2007, p. 11), the role that early childhood educators play in facilitating access to meaningful children's literature cannot be stressed enough (UNESCO, 2007). In professional practice, these important issues can be addressed through honest and open discussions and professional reflections. 


\section{Conclusion}

The findings of the present study can have a number of practical implications. Because this study revealed significant underrepresentation and gender stereotypes in analyzed children's books, it is advised that educators be observant of messages conveyed by the books they choose to have in early childhood settings. Educators need to be aware of gender issues in early childhood and gender patterns in children's books. Moreover, the importance of developing more gender-sensitive practice was highlighted in the present study findings. Because repeated exposition to biased representations could have dangerous consequences for children, reinforcing stereotypical gender patterns as part of their thinking (Santora, 2013), educators need to take responsibility to select books that contain accurate representations of all people. This research study hopes to help early childhood educators become aware of gender stereotyping in children's books. As is evident from the present findings, educators may be unaware of the gender patterns in the books they use in work with children.

Conducting a larger-scale research study that would explore gender representation in books used in early childhood setting is recommended. This would serve to understand the scale of potential underrepresentation and gender stereotyping in children's books and to prompt educators to pay more attention to the content of the books they are choosing to read with children. Another worthy objective for future research studies could be examining children's understandings of the messages they receive through the stories that are read to them.

\section{ORCID}

Katarina Filipović (DD http://orcid.org/0000-0003-4270-8202

\section{References}

Adams, M., Walker, C., \& O'Connell, P. (2011). Invisible or involved fathers? A content analysis of representations of parenting in young children's picturebooks in the UK. Sex Roles, 65, 259-270. doi:10.1007/s11199-011-0011-8

Aina, O. E., \& Cameron, P. A. (2011). Why does gender matter? Counteracting stereotypes with young children. Dimesions of Early Childhood, 39(3), 11-20.

Anderson, D. A., \& Hamilton, M. (2005). Gender role stereotyping of parents in children's picture books: The invisible father. Sex Roles, 52(3-4), 145-151. doi:10.1007/s11199-005-1290-8

Blake, J., \& Maiese, N. (2008). No fairytale... The benefits of the bedtime story. The Psychologist, 21(5), $386-388$.

Braun, V., \& Clarke, V. (2006). Using thematic analysis in psychology. Qualitative Research in Psychology, 3(2), 77101. doi:10.1191/1478088706qp063oa

Cherland, T. (2006). Female representation in children's literature. Ecclectica, 25(4), 284-290.

Crisp, T., Knezek, S. M., Quinn, M., Bingham, G. E., Girardeau, K., \& Starks, F. (2016). What's on our bookshelves? The diversity of children's literature in early childhood classroom libraries. Journal of Children's Literature, 42(2). Retrieved from https://www.questia.com/library/journal/1P3-4244130861/what-s-on-our-bookshelves-the-diversityof-children-s

Davies, B. (2003). Frogs, snails and feminist tales. Berkeley, CA: Hampton Press.

Derman-Sparks, L., \& Edwards, J. O. (2010). Anti-bias education for young children and ourselves. Washington, DC: National Association for the Education of Young Children.

Dewar, B. A., Servos, J. E., Bosacki, S. L., \& Coplan, R. (2013). Early childhood educators' reflections on teaching practices: The role of gender and culture. Reflective Practice, 14(3), 381-391. doi:10.1080/ 14623943.2013 .767234

Diekman, A. B., \& Murnen, S. K. (2004). Learning to be little women and little men: The inequitable gender equality of nonsexist children's literature. Sex Roles, 50(5/6), 373-385. doi:10.1023/B:SERS.0000018892.26527.ea

Frawley, T. J. (2008). Gender schema and prejudicial recall: How children misremember, fabricate, and distort gendered picture book information. Journal of Research in Childhood Education, 22(3), 291-303. doi:10.1080/ 02568540809594628

Gooden, A., \& Gooden, M. (2001). Gender representation in notable children's picture books: 1995-1999. Sex Roles, 45 (1/2), 89-101. doi:10.1023/A:1013064418674

Hamilton, M. C., Anderson, D., Broaddus, M., \& Young, K. (2006). Gender stereotyping and under-representation of female characters in 200 popular children's picture books: A twenty-first century update. Sex Roles, 55(11-12), 757765. doi:10.1007/s11199-006-9128-6 
Hunt, P. (2009). The world in pictures. In D. McCorquodale, S. Hallam, \& L. Waite (Eds.), Illustrated children's books (pp. 8-26). London, England: Black Dog.

Huntington, A. R. (2013). Breaking gender barriers in early childhood education: An exploration of the Reggio Emilia and Montessori approaches. The Loyola University Chicago Journal of Early Education Law and Policy, 2013, 1-14. Retrieved from https://www.luc.edu/media/lucedu/law/centers/childlaw/earlyeducation/2013studentpapers/hunting ton.pdf

Irvine, S., \& Price, J. (2014). Professional conversations: A collaborative approach to support policy implementation, professional learning and practice change in ECEC. Australasian Journal of Early Childhood, 39, 85-93.

Karlson, I., \& Simonsson, M. (2011). A question of gender-sensitive pedagogy: Discourses in pedagogical guidelines. Contemporary Issues in Early Childhood, 12(3), 274-283. doi:10.2304/ciec.2011.12.3.274

Kok, J. L., \& Findlay, B. (2006). An exploration of sex-role stereotyping in Australian award-winning children's picture books. The Australian Library Journal, 55(3), 248-261. doi:10.1080/00049670.2006.10721857

Kortenhaus, C. M., \& Demarest, J. (1993). Gender role stereotyping in children's literature: An update. Sex Roles, 28(34), 219-232. doi:10.1007/BF00299282

Larrivee, B. (2000). Transforming teaching practice: Becoming the critically reflective teacher. Reflective Practice, 1(3), 293-307. doi:10.1080/713693162

Louie, P. (2012). Not so happily ever after? The Grimm truth about gender representations in fairytales. Ignite: UBC Women's and Gender Studies Undergraduate Journal, 4(1), 74-82.

Lowery, R. M. (2002). Grappling with issues of gender equity: Preservice teachers' reflections on children's Books. Journal of Children's Literature, 28(2), 25-31.

Malaguzzi, L. (1993). Your image of the child: Where the teaching begins. Retrieved May 2016 from http://goo.gl/ NRgIBn

Marie, M. (2007). A thematic feminist analysis of best-selling children's picture books (master's thesis). Oregon State University. Retrieved from https://goo.gl/NsBMQs

McCabe, J., Fairchild, E., Grauerholz, L., Pescosolido, B. A., \& Tope, D. (2011). Gender in twentieth-century children's books: Patterns of disparity in titles and central characters. Gender \& Society, 25(2), 197-226. doi:10.1177/ 0891243211398358

Nair, R., \& Talif, R. (2010). Lexical choices and the construction of gender in Malaysian children's literature. Kajian Malaysia, 28(2), 137-159.

Paterson, S. B., \& Lach, M. A. (1990). Gender stereotypes in children's books: Their prevalence. Gender \& Education, 2 (2), 185-197. doi:10.1080/0954025900020204

Patt, M., \& McBride, B. (1993, April). Gender equity in picture books in preschool classrooms: An exploratory study. Paper presented at the Annual meeting of the American Educational Research Association, Atlanta, GA. Retrieved from http://files.eric.ed.gov/fulltext/ED362298.pdf

Paynter, K. C. (2011). Gender stereotypes and representation of female characters in children's picture books (Doctoral dissertation). Retrieved from http://digitalcommons.liberty.edu/cgi/viewcontent.cgi? article $=1500 \&$ context $=$ doctoral

Raikes, H., Alexander Pan, B., Luze, G., Tamis-LeMonda, C. S., Brooks-Gunn, J., Constantine, J., \& Rodriguez, E. T. (2006). Mother-child bookreading in low-income families: Correlates and outcomes during the first three years of life. Child Development, 77(4), 924-953. doi:10.1111/j.1467-8624.2006.00911.x

Reform. (2016). Nordic website for the promotion of gender equality in children's literature and day care. Retrieved from http://genustest.no/about-the-website/?lang=en

Roper, E. A., \& Clifton, A. M. (2013). The representation of physically active girls in children's picture books. Research Quarterly for Exercise and Sport, 84, 147-156. doi:10.1080/02701367.2013.784844

Ruterana, P. C. (2012). Children's reflections on gender equality in fairy tales: A Rwanda case study. Journal of Pan African Studies, 4, 85-101.

Santora, L. A. (2013). Assessing children's book collections using anti-bias lens. New York, NY: New York AntiDefamation League.

Stanfield, R. B. (Ed). (2000). The art of focused conversation: 100 ways to access group wisdom in the workplace. Toronto, Canada: Canadian Institute of Cultural Affairs.

Taber, N., \& Woloshyn, V. (2011). Issues of exceptionality, gender, and power: Exploring Canadian children's awardwinning literature. Gender and Education, 23(7), 889-902. doi:10.1080/09540253.2010.549112

Tagnoli, J., Pullen, J., \& Lieber, J. (1994). The privilege of place: Domestic and work locations of characters in children's book. Children's Environments, 11(4), 272-280.

Tainio, L., \& Karvonen, U. (2015). Finish teachers exploring gender bias in school textbooks. In S. Mills \& A. S. Mustapha (Eds.), Gender representation in learning materials. New York, NY: Routledge.

Taylor, F. (2003). Content snalysis and gender dtereotypes in children's books. Teaching Sociology, 31(3), 300-311. doi: $10.2307 / 3211327$

Toçi, A., \& Aliu, M. (2013). Gender stereotypes in current children's English books used in elementary schools in the Republic of Macedonia. American International Journal of Contemporary Research, 3(12), 32-38.

Tsao, Y. (2008). Gender issues in young children's literature. Reading Improvement, 45(3), 108-114. 
UNESCO. (2007). Strong foundations for gender equality in early childhood care and education - advocacy brief. Bangkok, Thailand: Author.

Weitzman, L. J., Eifler, D., Hokada, E., \& Ross, C. (1972). Sex-role socialization in picture books for preschool children. American Journal of Sociology, 77(6), 1125-1150. doi:10.1086/225261

Zaman, A. (2008). Gender sensitive teaching: A reflective approach for early childhood education teacher training programs. Education, 129(1), 110-118.

\section{Appendix A. Books sample}

\begin{tabular}{|c|c|c|c|c|c|}
\hline & Book title & Author & Illustrator & $\begin{array}{l}\text { Publication } \\
\text { (original publication year) }\end{array}$ & $\begin{array}{l}\text { Children's } \\
\text { group }\end{array}$ \\
\hline 1 & Owl Babies & Martin Waddell & Patrick Benson & O'Brien Press, 1994 (1992) & Waddlers \\
\hline 2 & We're Going on a Bear Hunt & Michael Rosen & $\begin{array}{l}\text { Helen } \\
\text { Oxenbury }\end{array}$ & Walker Books, 1993 (1989) & Waddlers \\
\hline 3 & $\begin{array}{l}\text { Brown Bear, Brown Bear, What Do You } \\
\text { See? }\end{array}$ & Bill Martin, Jr. & Eric Carle & Puffin Books, 1995 (1967) & Waddlers \\
\hline 4 & Dear Zoo & Rod Campbell & Rod Campbell & Puffin Books, 2008 (1982) & Waddlers \\
\hline 5 & The Very Hungry Caterpillar & Eric Carle & Eric Carle & Puffin Books, 2002 (1969) & Toddlers \\
\hline 6 & The Very Busy Bee & Caterpillar Books & Jack Tickle & $\begin{array}{l}\text { Little Tiger Press, } 2008 \\
\text { (2005) }\end{array}$ & Toddlers \\
\hline 7 & We All Go Traveling By & Sheena Roberts & Siobhan Bell & Barefoot Books, 2011 (2003) & Toddlers \\
\hline 8 & Little Puppy & Emma Goldhawk & $\begin{array}{l}\text { Jonathan } \\
\text { Lambert }\end{array}$ & Templar, 2010 & Toddlers \\
\hline 9 & Monkey Puzzle & Julia Donaldson & Axel Scheffler & $\begin{array}{l}\text { Macmillan Children's Books, } \\
2000\end{array}$ & Preschoolers \\
\hline 10 & Supermarket Zoo & Carly Isaac & Edward Eaves & Simon and Schuster, 2010 & Preschoolers \\
\hline 11 & Caterpillar Spring: Butterfly Summer & Susan Hood & Claudine Gevry & Reader's Digest, 2003 & Preschoolers \\
\hline 12 & Five Little Speckled Frogs & Nursery rhyme & Joanne Parry & $\begin{array}{l}\text { Ginger Fox Ltd. (year } \\
\text { unknown) }\end{array}$ & Preschoolers \\
\hline 13 & Monkey Business & $\begin{array}{l}\text { Smriti Prasadam } \\
\text { Halls }\end{array}$ & $\begin{array}{l}\text { David } \\
\text { Wojtowycz }\end{array}$ & Orchard Books, 2013 & Preschoolers \\
\hline 14 & $\begin{array}{l}\text { Polar Bear, Polar Bear, What Do You } \\
\text { Hear? }\end{array}$ & Bill Martin Jr. & Eric Carle & Puffin Books, 1994 (1991) & Preschoolers \\
\hline 15 & Elephant Pants & $\begin{array}{l}\text { Smriti Prasadam } \\
\text { Halls }\end{array}$ & $\begin{array}{l}\text { David } \\
\text { Wojtowycz }\end{array}$ & Orchard Books, 2012 & Preschoolers \\
\hline
\end{tabular}




\section{Appendix B. Analysis form}

Book title:

Author(s):

Illustrator(s):

Publication:

Children's group:

BOOK SUMMARY: What is this book about? Who is/are the main character/s?

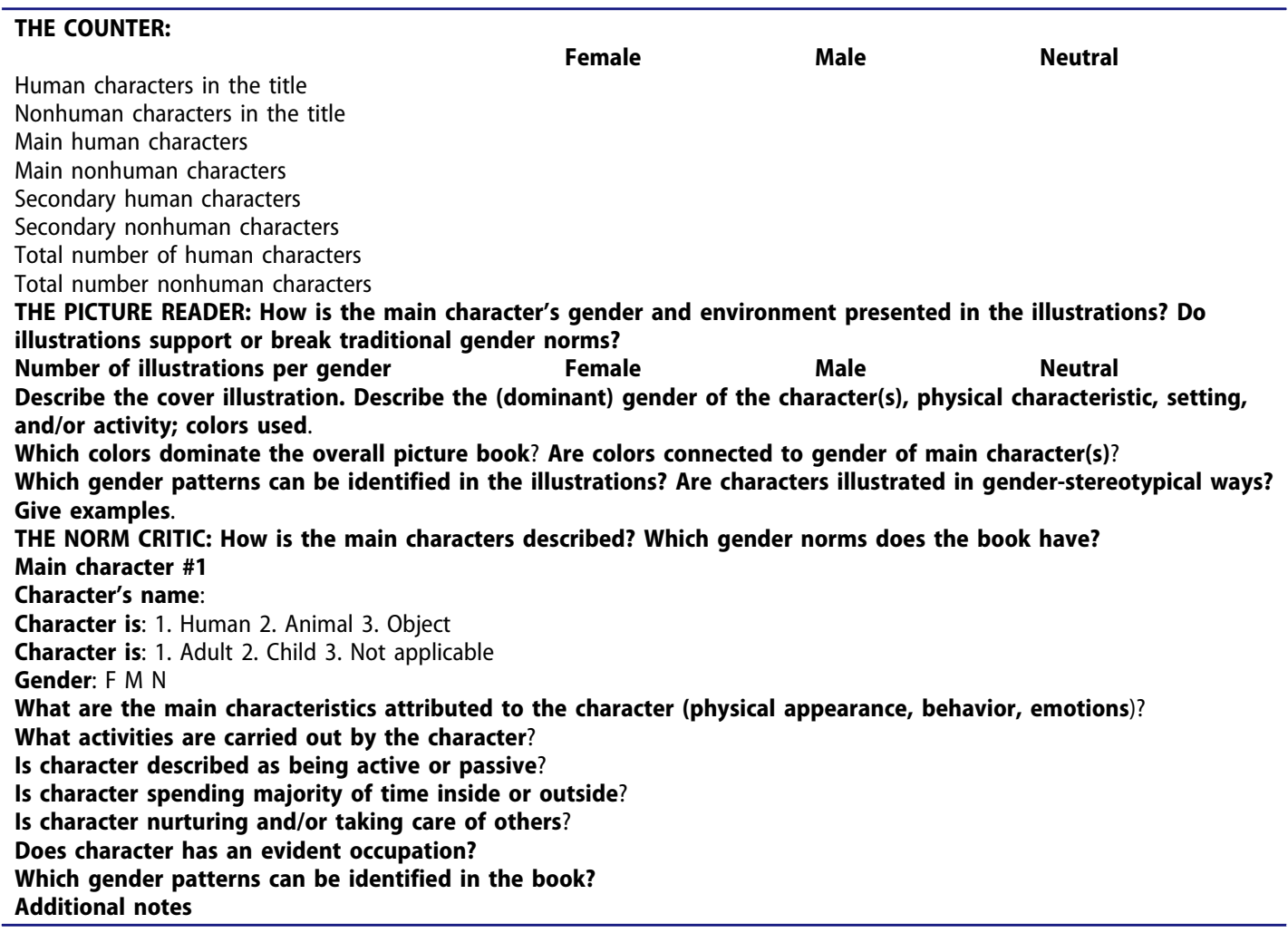

